\title{
Modeling Wind Turbines in the Simulation of Power System Dynamics
}

\author{
Istvan Erlich, University of Duisburg-Essen, Fekadu Shewarega, University of Duisburg-Essen, \\ Oliver Scheufeld, FGH Test Systems GmbH
}

\begin{abstract}
This paper deals with the modeling of variable speed wind turbines for stability studies. Using the space-phasor representation and the fundamental relationships governing the operation of the machine quasi stationary model, suitable control algorithms for the simulation of the doubly-fed induction machine (DFIM) as well as the permanent magnet synchronous machine (PMSM) operating on an interconnected system are developed. The control schemes include the pitch-angle/speed control and the decoupled control of the real and reactive power outputs. As an additional modeling option, the generic model for variable speed machine has been introduced. The models were then implemented on a representative test network, and simulations have been carried out to observe the response of the control system to typical abnormal situations such as three phase grid faults to compare the accuracy of the generic models with the detailed quasi-stationary (QSS) models.
\end{abstract}

Keywords: wind power, control system, power system stability, doubly-fed induction machine.

\section{INTRODUCTION}

$\mathrm{T}$ HE past two decades have seen the emergence of wind as the world's fastest growing renewable energy source. During this period the share of wind power in relation to the overall installed capacity has increased significantly and this trend is in all likelihood set to continue. As the obvious choice for electromechanical energy conversion either the induction or the synchronous generator (appropriately designed and configured for wind turbines) come into question. The modelling of these two types of machines and their control systems is the focus of this paper.

Generators based on the DFIM concept consist of a slipring induction generator whose rotor is connected to the grid through a back-to-back converter. The major advantage of this design over the synchronous machine is the fact that the converter has to be sized only for about one-thirds of the machine rating. However, since it is not fully decoupled from the grid, the machine is directly affected by grid disturbances. Wind turbines with synchronous generator use a frequency converter, which needs to be rated for the full machine rating, and, as a result, the converter of this type of machine is referred to as the full-size converter. The converter enables operation of the WT in a wide speed range. The machine is fully decoupled from the grid, and can, as a result, operate at

I. Erlich (e-mail: istvan.erlich@uni-duisburg.de) and F. Shewarega (e-mail: fekadu.shewarega@uni-duisburg.de) are with the University Duisburg-Essen, 47057 Duisburg, Germany ; O. Scheufeld (email: oliver.scheufeld@fghma.de) is with FGH e.V., 52072 Aachen, Germany. normal voltage and output power even during faults. The common feature in both cases is the field oriented control (FOC), which enables the decoupled control of active and reactive power outputs.

This paper is aimed at providing an overview of the current state-of-the-art in modeling variable speed machines together with their control system for large-scale system studies. The system of machine equations as presented here are directly applicable only to the DFIM, but only minor modifications are needed to adapt them to the synchronous machine. Based on the fundamental equations governing the operation of the machine the quasi-stationary model of the DFIM will be derived. Then, the control structure will be introduced, which includes the speed and pitch-angle control as well as the fast, decoupled electrical control of $\mathrm{P}$ (active power) $\mathrm{Q}$ (reactive power). The same procedure will be followed for the modeling of the direct drive synchronous machine. Finally, the proposed generic models for wind turbines will be presented and simulation results comparing the various modeling options will be provided.

\section{A. Mathematical model of the DFIM}

What distinguishes the DFIM from ordinary slip-ring induction machine is the fact that the rotor terminals are fed with a symmetrical three-phase voltage of variable frequency and amplitude from the grid via a voltage source converter usually equipped with IGBT based power electronic circuitry. The basic structure is shown in Fig. 1Fig. 1.

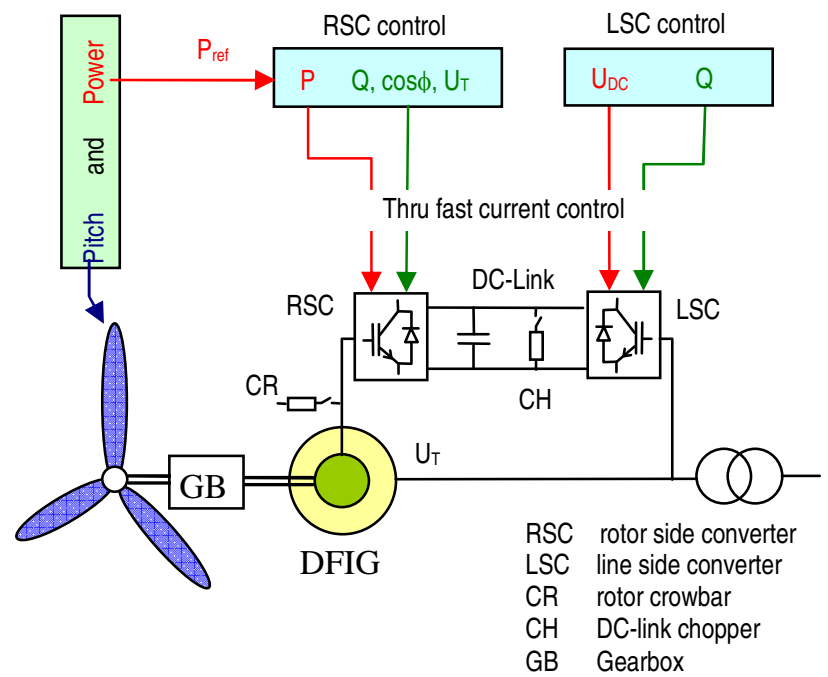

Fig. 1. The main components of the DFIG system. 
The variable rotor voltage enables the machine to operate at adjustable rotor speed to match the optimum operating point corresponding to a given wind speed. The dimensioning of the rotor power depends on the desired rotor speed change $(\Delta \omega)$ between cut-in and maximum wind speeds. The converter enables the machine to operate in all four quadrants in the complex P-Q plane including delivering reactive power to the grid. Additionally, $\mathrm{Q}$ delivered to or absorbed form the grid can be controlled independently from the real power output. Protection against overcurrents or excessive DC voltage is provided by the crowbar (CBR) connected to the rotor.

\section{1) Detailed model}

For modeling rotating machines the space phasor representation using complex vectors (underlined variables) containing orthogonal direct (d) and quadrature (q) axis components is used. Equations (1)-(5) represent the complete set of mathematical relationships that describe the dynamic behavior of the machine. All quantities are in per unit (p.u.) and a sign convention, which results in positive sign for consumed power, has been used.

\section{Voltage equations:}

$$
\begin{aligned}
& \underline{u}_{S}^{\angle K}=r_{S} \underline{i}_{S}^{\angle K}+d \underline{\psi}_{S}^{\angle K} / d t+j \omega_{K} \underline{\psi}_{S}^{\angle K} \\
& \underline{u}_{R}^{\angle}=r_{R} \cdot \underline{i}_{R}^{L}+d \underline{\psi}_{R}^{\angle} / d t+j \cdot\left(\omega_{K}-\omega_{R}\right) \cdot \underline{\psi}_{R}^{\angle}
\end{aligned}
$$

The subscripts $\mathrm{S}$ and $\mathrm{R}$ denote, respectively, stator and rotor and $\omega_{\mathrm{K}}$ represents the speed of the rotating reference frame.

\section{Flux linkages:}

$$
\begin{aligned}
& \underline{\psi}_{S}^{<}=l_{S} \cdot \underline{i}_{S}^{L}+l_{h} \cdot \underline{i}_{R}^{<} \\
& \underline{\psi}_{R}^{<}=l_{h} \cdot \underline{i}_{S}^{<}+l_{R} \cdot \underline{i}_{R}^{\angle}
\end{aligned}
$$

where $l_{S}=l_{h}+l_{\sigma S}$ and $l_{R}=l_{h}+l_{\sigma R}$

\section{Equation of motion:}

$$
d \omega_{R} / d t=\left(\psi_{S d}^{\llcorner} i_{S q}^{<}-\psi_{S q}^{\llcorner} i_{S d}^{<}+t_{m}\right) / T_{m}
$$

Equations (1) and (2) resolved into real and imaginary parts together with (5) constitute the $5^{\text {th }}$ order model of the DFIM. The stator terminal voltage $\underline{u}_{S}^{<}$forms the link to the external network. It should however be noted that the use of the $5^{\text {th }}$ order model is clearly not feasible for large scale stability simulation, and, as a result, a reduced order or quasi-stationary model needs to be derived.

\section{2) Reduced order dynamic model}

The reduced order or the so-called quasi steady state (QSS) model can be obtained by neglecting the derivative term in (1). From this point onwards the synchronously rotating reference frame will be adopted but the superscript $\angle \omega_{0}$ will be abandoned for simplicity of notation. It then follows from (1) for the stator flux linkages:

$$
\underline{\psi}_{S}=\left(\underline{u}_{S}-r_{S} \underline{i}_{S}\right) / j \omega_{0}
$$

Similarly, another expression for the stator flux linkages can be obtained by eliminating the rotor current in (3) using (4). Thus,

$$
\underline{\psi}_{S}=l_{S} \underline{i}_{S}+\left(\underline{\psi}_{R}-l_{h} \underline{i}_{S}\right) \cdot l_{h} / l_{R}
$$

From Eq. (6) and (7) we have:

$$
\underline{u}_{\mathrm{S}}-r_{s} \underline{i}_{\mathrm{S}}=j \omega_{0}\left\lfloor l_{S} \underline{i}_{\mathrm{S}}+\left(\underline{\psi}_{\mathrm{R}}-l_{h} \underline{i}_{\mathrm{S}}\right) \cdot l_{h} / l_{R}\right\rfloor
$$

which, after rearrangement, results in:

$$
\underline{u}_{S}=\underline{z}^{\prime} \underline{i}_{S}+\underline{u}^{\prime}
$$

where

$$
\underline{z^{\prime}}=\left(r_{S}+j \omega_{0} l^{\prime}\right)
$$

is defined as the internal transient impedance and

$$
\underline{u}^{\prime}=j \omega_{0} k_{R} \underline{\psi}_{R}
$$

as the transient Thévenin voltage source, with $l^{\prime}=l_{s}-l_{h}^{2} / l_{R}$ and $k_{R}=l_{h} / l_{R}$

The voltage equation (9) can be illustrated using the equivalent circuit given in Fig. 2.

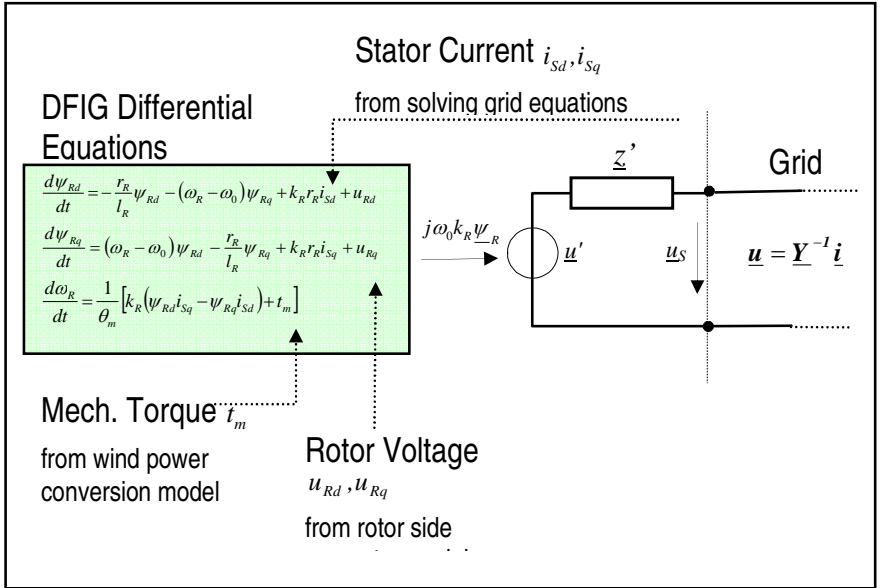

Fig. 2. Reduced order DFIG model with coupling to the grid.

The internal voltage in Fig. $2\left(\underline{u}^{\prime}\right)$ is a function of the d- and q-components of the rotor flux, which together with the rotor speed are state variables of the reduced order model. The state-space differential equations themselves can be obtained from (2) after eliminating the rotor current using (4). The resulting relationship resolved into $\mathrm{d}$ - and q-components is:

$$
\begin{aligned}
& d \psi_{R d} / d t=-\psi_{R d} \cdot r_{R} / l_{R}+\left(\omega_{R}-\omega_{0}\right) \psi_{R q}+k_{R} r_{R} i_{S d}+u_{R d} \\
& d \psi_{R q} / d t=\left(\omega_{R}-\omega_{0}\right) \psi_{R d}-\psi_{R q} \cdot r_{R} / l_{R}+k_{R} r_{R} i_{S q}+u_{R q}
\end{aligned}
$$

To complete the QSS model, the equation of motion (5) needs to be modified to take account of the fact that the stator flux is now no longer a state variable. This is achieved by eliminating the stator flux first using (3) and then the rotor current using (4), which results in:

$$
d \omega_{R} / d t=\frac{1}{T_{m}}\left[k_{R}\left(\psi_{R d} i_{S q}-\psi_{R q} i_{S d}\right)+t_{m}\right]
$$

Equations (11) - (13) constitute the QSS ( $3^{\text {rd }}$ order) model of the induction machine.

\section{B. Model of the control system}

The control system of the DFIM encompasses the speed/pitch-angle control and the control systems associated with the grid side as well as the rotor side converters. 
1) Speed/pitch-angle control and model of the wind power conversion system

The mechanical power extracted from the wind can be calculated as:

$$
p_{T}=\rho A_{r o t} C_{p}(\lambda, \beta) v_{w}^{3} / 2
$$

where

$\rho$ : air density; $A_{\text {rot }}$ :cross-sectional area traversed by the turbine; $C p$ : power coefficient, $v_{W}$ : wind speed; $\beta$ : the pitchangle; $\lambda$ : tip-speed ratio.

Wind turbines provide two degrees of freedom for control, namely turbine speed and the blade pitch-angle. At partial loads the pitch angle is adjusted for capturing the maximum wind power at constant pitch angle but variable rotor speed. The upper part of Fig. 3 shows an example of a control structure for keeping the rotor speed within the desired range. The output of this controller serves as the set point for the rotor side converter control. Both partial and full load turbine controls can be modeled as shown in Fig. 3. The optimal rotor speed depending on the wind speed is described by a characteristic lookup table shown in the upper left corner (Fig. 3 ). When the nominal wind speed (approximately at $12 \mathrm{~m} / \mathrm{s}$ ) is reached the lower speed controller is activated to pitch the blades and thus to reduce the power generated. The angle $\beta_{0}$ represents the set point in partial load mode. The output $\beta_{\text {ref }}$ is provided to the blade actuator which is represented by a first order delay. The calculation of the turbine power $p_{m}$ and torque $t_{m}$ is needed only for the evaluation of Eq. (13).
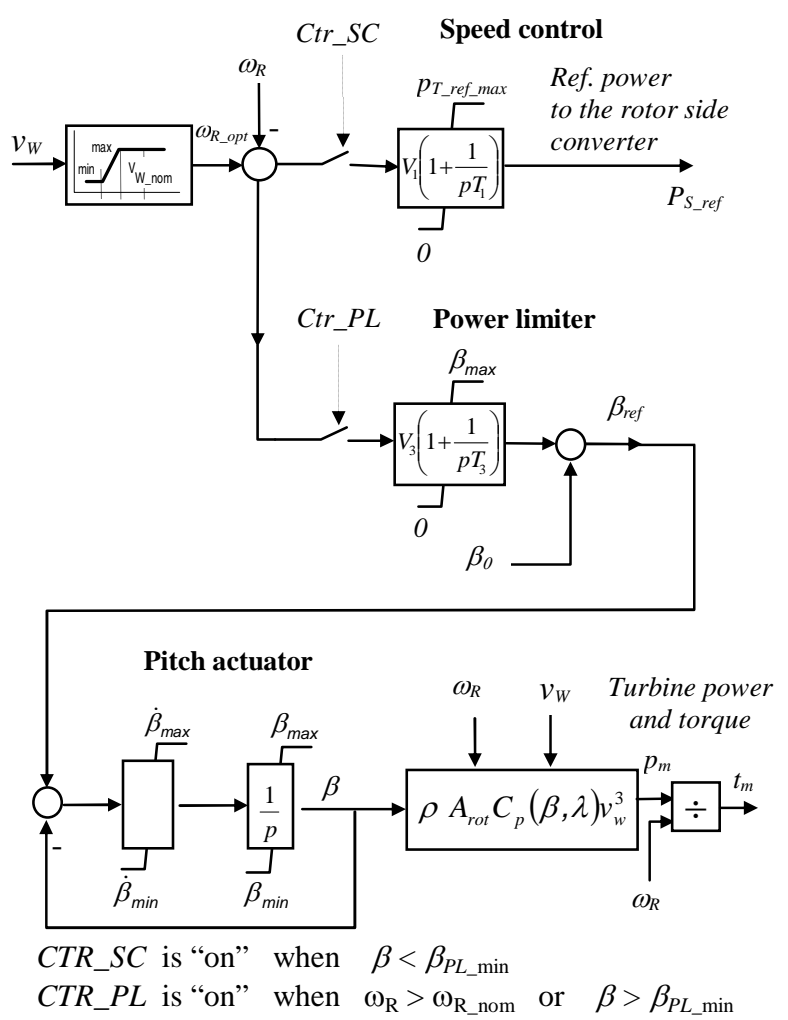

Fig. 3. Wind turbine converter control model.

2) Control and modeling of the rotor side converter

The rotor side converter is used to control $\mathrm{P}$ and $\mathrm{Q}$ outputs of the machine[4], [5]. The extraction of maximum energy from the wind necessitates the adjustment of the rotor speed to correspond to the changing wind speed. Therefore, the reference power provided to the converter control is derived from the wind speed [4], [5], as shown in Fig. 3.

Independent control of $\mathrm{P}$ and $\mathrm{Q}$ can be achieved through rotor current control [1], [2]. It follows from Eq. (5) that the electrical torque keeping balance with the mechanical turbine torque is calculated using the equation:

$$
t_{e l}=\psi_{S d}^{<} i_{S q}^{<}-\psi_{S q}^{<} i_{S d}^{<}
$$

Assuming an orthogonal coordinate system where the real axis corresponds with the direction of the stator flux (d-axis), i.e. $\psi_{S d}^{\angle \psi_{S}}=\left|\underline{\psi}_{S}\right|$ leads to $\psi_{S q}^{\angle \psi_{S}}=0$, which in turn leads to:

$$
t_{e l}=\left|\underline{\psi}_{S}\right| i_{S q}^{\angle \psi_{S}}
$$

One can easily deduce (from (16)) that electrical torque can be controlled through the control of the q-axis component of the stator current. Alternatively, if the d-axis is chosen to coincide with the stator voltage phasor, the d-component of the stator current is equal to the active current and the qcomponent corresponds to the negative of the reactive current.

Control of the DFIM takes place essentially from the rotor side. To calculate the reference values for rotor currents, the steady state relationship between rotor and stator currents is required. Using Eq. (1) and (3) (after neglecting the derivative term and setting $\left.r_{\mathrm{S}}=0\right)$, it can be shown that:

$$
\begin{aligned}
& i_{R d_{-} r e f}^{\angle u_{S}}=-p_{S_{-} \text {ref. }} \cdot x_{S} /\left(\left|u_{S}\right| \cdot x_{h}\right) \\
& i_{R q_{-} \text {ref }}^{\angle u_{S}}=q_{S_{-} \text {ref. }} x_{S} /\left(\left|u_{S}\right| \cdot x_{h}\right)-\left|\underline{u}_{S}\right| / x_{h}
\end{aligned}
$$

Practical requirements dictate that a delay term is introduced before passing $p_{S_{-} r e f}$ and $q_{S_{-} r e f}$ on to the current controller. The term $\left|\underline{u}_{S}\right| / x_{h}$ represents the magnetization current that additionally has to be provided from the rotor side. Fig. 4 shows the control and simulation structure derived from Eq. (17) and (18).

Fig. 4 has been augmented by a fast-acting voltage controller. The gain and time constant to be chosen depend on the stability requirements of the system, which has to take precedence at all times [1]. 




Fig. 4. Structure for generating rotor current reference values.

The next question concerns the control loop of the rotor current and how the corresponding rotor voltage is to be calculated. It follows from (1) and (2) together with (3) and (4) (after setting the flux derivative terms zero) that:

$$
\begin{aligned}
& u_{R d}^{\angle u_{S}}=r_{R} i_{R d}^{\angle u_{S}}+s\left(\left|\underline{u}_{S}\right| \cdot x_{h} / x_{S}-i_{R q}^{\angle u_{S}} \sigma x_{R}\right) . \\
& u_{R q}^{\angle u_{S}}=r_{R} i_{R q}^{\angle u_{S}}+s i_{R d}^{\angle u_{S}} \sigma x_{R}
\end{aligned}
$$

$$
\text { where } \sigma=\left(1-x_{h}^{2} / x_{R} x_{S}\right) \text { (the leakage coefficient). }
$$

The voltage drops over the rotor resistance in (19) and (20) can be interpreted as auxiliary signals which are outputs of the intended rotor current controller. Assuming PI controllers, the control transfer functions then become:

$$
\begin{aligned}
& u_{R d}^{\prime<u_{S}}=r_{R} i_{R d}^{\angle u_{S}}=K_{I}\left(1+1 /\left(p T_{I}\right)\right) \cdot\left(i_{R d_{-} r e f}^{\angle u_{S}}-i_{R d}^{\angle u_{S}}\right) \\
& u_{R q}^{\prime<u_{s}}=r_{R} i_{R q}^{\angle u_{S}}=K_{I}\left(1+1 / p T_{I}\right) \cdot\left(i_{R q_{-} r e f}^{\angle u_{s}}-i_{R q}^{\angle u_{S}}\right)
\end{aligned}
$$

The corresponding block diagram of the rotor current controller is shown in Fig. 5.

To be able to pass the outputs $u_{R d}^{\angle u_{S}}$ and $u_{R q}^{\angle u_{S}}$ in a practical situation as reference values to the rotor side converter control, the signals have to be transformed into the rotor reference frame.

3) Control and modeling of the grid side converter

The grid and rotor side converters are linked through a DC capacitor. If the DC voltage is assumed to remain within limits an explicit representation of the DC circuit can be omitted for stability kind of power system simulations.

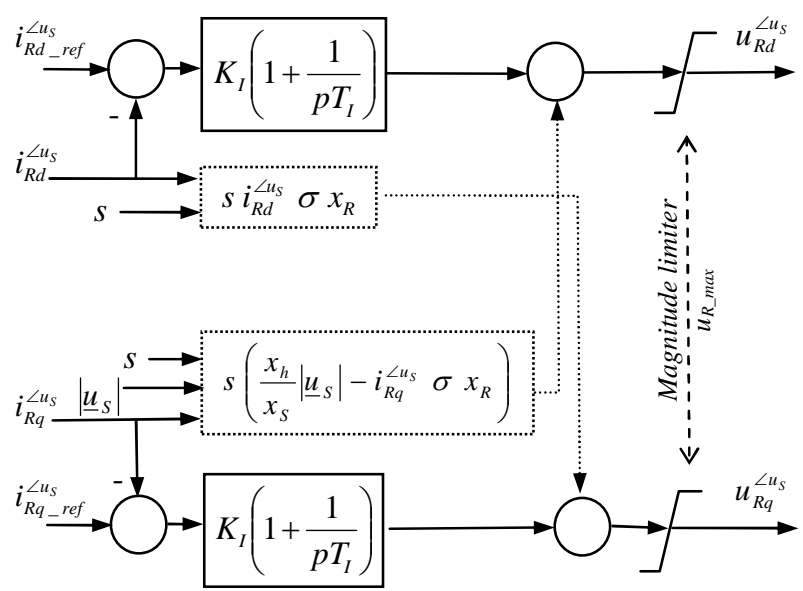

Fig. 5. Rotor current control.

The control of the grid side converter is similar to that of the rotor side. However, in the active power channel the DC voltage is controlled. This is achieved when the active power passing through both converters (the grid side and the rotor side) is in equilibrium. Therefore, the grid side converter will try to inject the same active power into the grid as that provided to the DFIM through the rotor side converter. Following the assumption that DC voltage fluctuations are not considered, the active power is injected into the grid without any time lag. After neglecting converter losses, we have for the corresponding power:

$$
p_{C G}=p_{R}=u_{R d}^{<} i_{R d}^{<}+u_{R q}^{<} i_{R q}^{<}
$$

The reactive power control channel of the grid side converter provides the capability to generate reactive power. However, in normal operation it is more practical to generate reactive power using the rotor side converter. The current transmitted from the rotor to the stator circuits is amplified on account of the typical values of the turns-ratio of the DFIM. Thus, the same reactive current passing through the rotor side converter is capable of producing higher reactive power compared to the current through the grid side converter. As a result, in normal operation, the reactive power reference value of the grid side converter is usually set to zero and the required reactive current is supplied by the rotor side converter. Fig. 6 shows a simple model of the grid side converter applicable for stability studies [3].

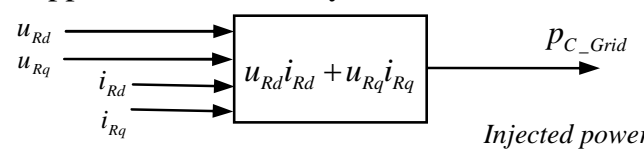

grid side converter terminal node

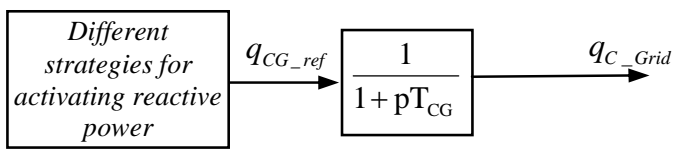

Fig. 6. Grid side converter model. 


\section{CONTROL OF A PERMANENT MAGNET SYNCHRONOUS GENERATOR (PMSG) BASED WT}

Wind turbines with PMSG use a frequency converter dimensioned for the full machine rating. The converter enables operation of the WT in a wide speed range. The machine is fully decoupled from the grid, and can, as a result, operate at normal voltage and output power during faults. (But the power output during faults is limited by the reduced voltage and converter current limits.) The configuration of a PMSG based wind turbine is shown in Fig. 7.

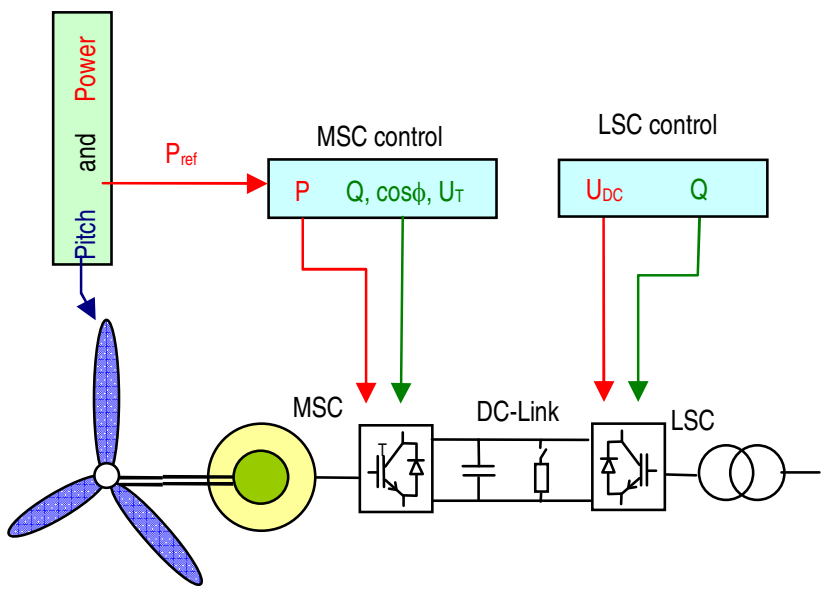

Fig. 7. PMSG wind turbine system with full-size converter.

\section{A. Line side converter (LSC) control}

The LSC control of the full-size converter is very similar to that of the DFIM. The only significant difference is that the whole generated power is fed into the grid through the converter. Additionally, the LSC has to provide the whole reactive current for grid voltage support during faults as well as in steady-state. The control structure of the LSC is shown in Fig. 8 and Fig. 9.

\section{B. Machine side converter (MSC) control}

In steady-state operation the performance of the PMSM is described by the system of equations (similar to those of DFIM) to develop the current control loop of the machine side converter. The voltage drop over the stator resistance is used as an auxiliary signal controlled by a PI controller. Fig. 10 and Fig. 11 show the requisite current control structure and the transformations required.

The transformation between the stator and rotor coordinate systems requires the angle $\alpha$ (the angle between stator voltage and rotor $\mathrm{q}$ axis). In a simulation environment all angles are known, and, therefore, no additional effort is necessary. The active current reference delivered by the active power controller ensures the injection of the active power generated by the wind. The reactive current control channel is usually used to keep the PMSM terminal voltage constant.

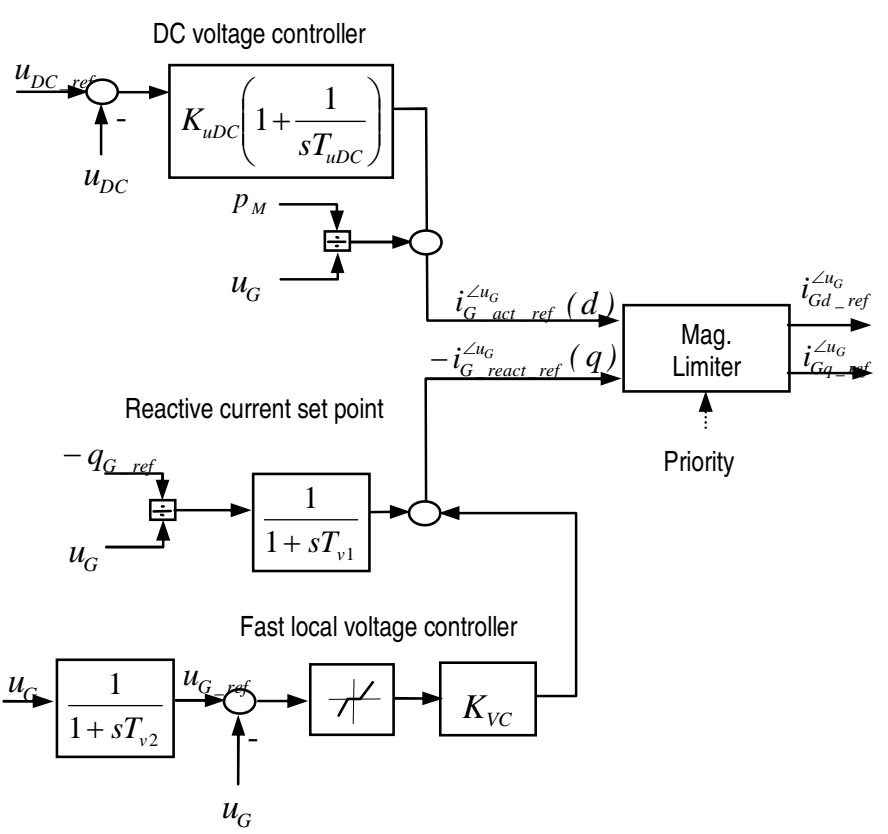

Fig. 8. LSC active and reactive current reference generation.

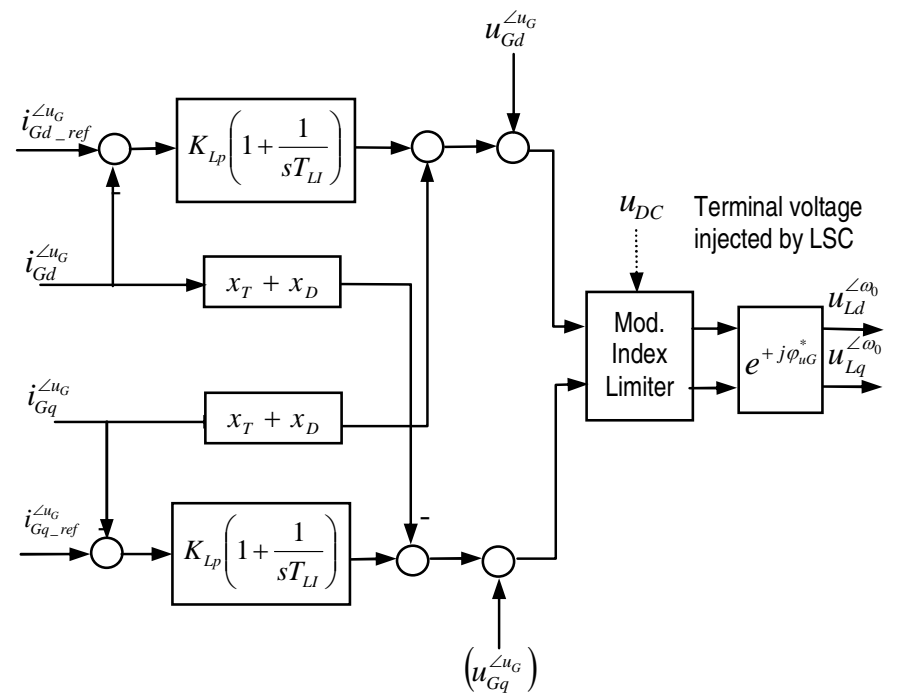

Fig. 9. LSC current controller.

\section{GENERIC MODEL OF VARIABLE SPEED WIND TURBINES}

In the preceding sections models applicable for both variable speed type wind turbines was introduced. Typically, these models are used to determine the power and voltage at grid connection point for different operating conditions. They can also be used to evaluate the behavior and impact of the wind farm on the rest of the grid in contingency situations. This enables full understanding of the characteristic behavior of wind turbines, the formulation of general connection requirements. The drawback of such a modeling approach, however, is that the models are different for different generator technologies such the DFIM and PMSG. Additionally, models are not only technology dependent but also manufacturer specific [6].

To overcome these problems generic dynamic model for simulating wind turbines in power system studies is increasingly becoming an attractive alternative. The basic building-blocks of any such models are available in practically 
all popular power system simulation packages. As a result the model can easily be made compatible across simulation platforms and can form the basis for standard models with appropriately adjusted parameters- thus underlining the need for a generic model non-proprietary, not linked to a certain turbine technology or manufacturer, applicable for all types of wind turbines, and compatible across simulation platforms. One such model is given in Fig. 12.

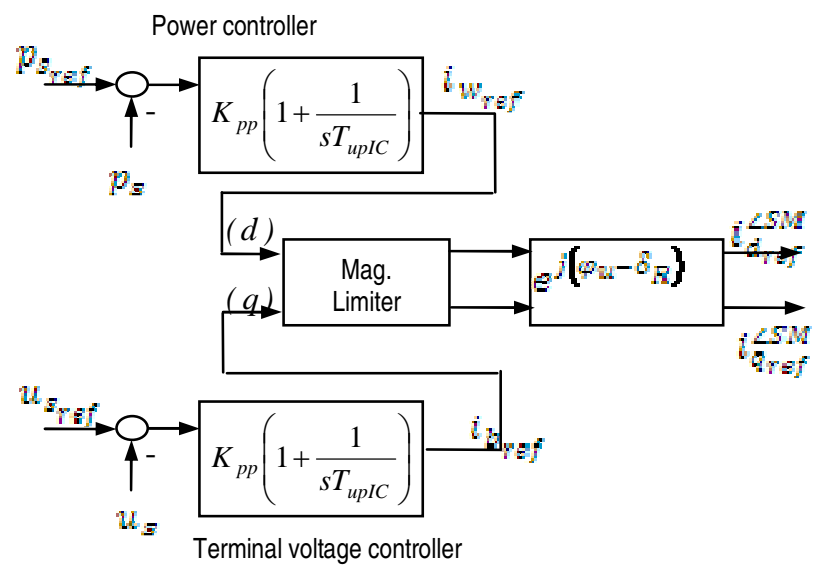

Fig. 10. MSC active and reactive current reference generation

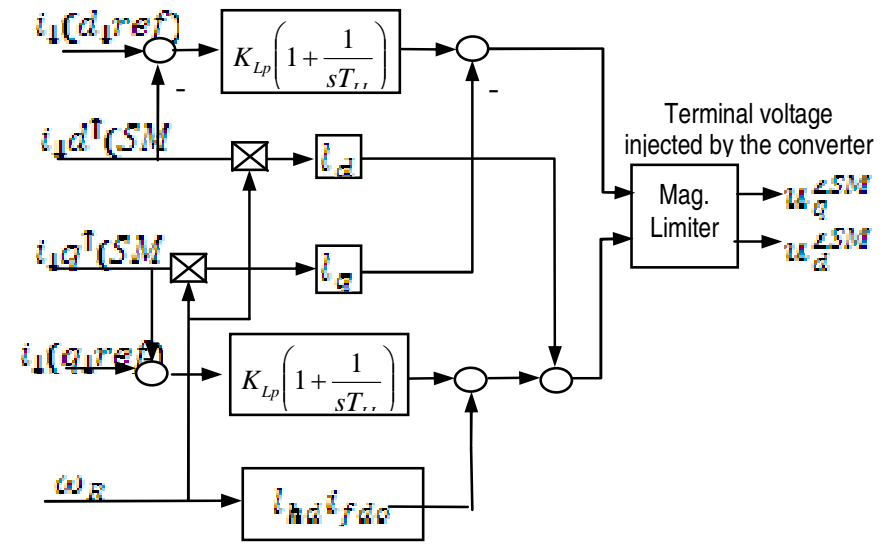

Fig. 11. MSC current controller

Fig. 13 and Fig. 14 compare simulation results obtained using the detailed QSS model on the one hand and a generic model on the other. In both cases a fault was introduced which reduces the terminal voltage to $50 \%$ of its original value. The resulting active current versus time (Fig. 13) and reactive current versus time (Fig. 14) are plotted.



Fig. 12. Type 3.3 Generic Model.

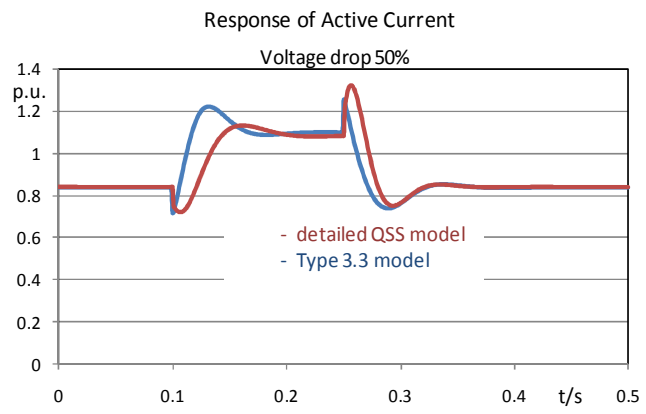

Fig. 13. Active current comparison: detailed QSS vs. generic models.

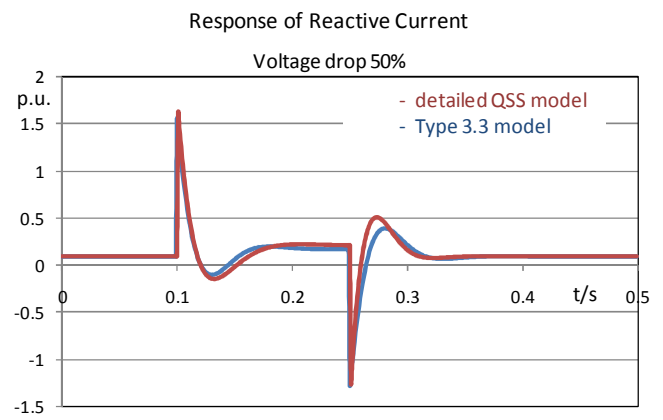

Fig. 14. Reactive current comparison: detailed QSS vs. generic models.

\section{CONCLUSION}

The modelling of variable speed wind turbines in power system stability studies has been the focus of this paper. The QSS model based on space-phasor representation was expanded to include models for the speed/pitch angle control and those associated with the grid and rotor side converters. The control algorithms were derived considering the need for the decoupled control of $\mathrm{P}$ and $\mathrm{Q}$ outputs of the machine. A similar approach has been used to obtain the control structures for the PMSG based wind turbines. As an alternative to the detailed models derived on the basis of physical relationships, a generic model has been introduced.

For comparing the generic model with the detailed QSS model a three-phase distant short circuit in the grid, which reduces the terminal voltage to $50 \%$ of its pre-fault value, was simulated for purposes of illustration. The results show that it is, in principle, possible to represent wind turbines with generic models that can be parametrically adjusted to any practical implementation.

\section{REFERENCES}

[1] Feltes, C.; Wrede, H. \& Erlich, I., "Dynamic Behaviour of DFIG-Based Wind Turbines During Grid Faults", IEEJ Transactions on Industry Applications, 2008 Vol. 128 No. 4 pp. 396 - 401

[2] P. Ledesma, J. Usaola, "Doubly Fed Induction Generator Model for Transient Stability Analysis", IEEE Trans. on Energy Conversion, vol. 20, pp. 388-397, Jun. 2005.

[3] J. B. Ekanayake, L. Holdsworth, X.G. Wu, N. Jenkins, "Dynamic Modeling of Doubly Fed Induction Generator Wind Turbines", IEEE Trans. on Power Systems vol. 18, pp. 803-809, May. 2003.

[4] T. Sun, Z. Chen, F. Blaabjerg, „Voltage Recovery of Grid-Connected Wind Turbines with DFIG After a Short-Circuit Fault", $35^{\text {th }}$ Annual IEEE Power Electronics Conf., Aachen, Germany, 2004, pp. 1991-1997. 
[5] P. Cartwright, L. Holdsworth, J.B. Ekanayake, N. Jenkins, "Coordinated voltage control strategy for a doubly-fed induction generator (DFIG)-based wind farm" ", IEE Proc.-Gener. Transm. Distrib. vol. 151, pp. 495-502, July. 2004

[6] Generic Wind Models for PSS®E Stability Simulation, Siemens PTI
eNewsletter
Issue
103 ,
https://www.ptius.com/pti/company/eNewsletter/2009January/Generic_Wind_Models_f or_PSSE_Stability_Simulation.htm

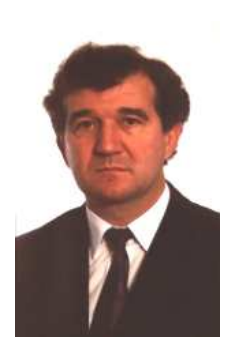

Istvan Erlich (1953) received his Dipl.-Ing. degree in electrical engineering from the University of Dresden/Germany in 1976. After his studies, he worked in Hungary in the field of electrical distribution networks. From 1979 to 1991, he joined the Department of Electrical Power Systems of the University of Dresden again, where he received his $\mathrm{PhD}$ degree in 1983. Since 1998, he is Professor and head of the Institute of Electrical Power Systems at the University of Duisburg-Essen/Germany. His major scientific interest is focused on power system stability and control, modelling and simulation of power system dynamics including intelligent system applications. He is a member of VDE and senior member of IEEE.

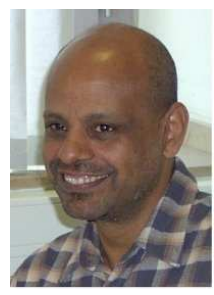

Fekadu Shewarega (1956) received his Dipl.-Ing degree in electrical engineering from the Technical University of Dresden, Germany in 1985. From 1985 to 1988 he pursued his postgraduate studies at the same university in the area of the simulation of power system dynamics and obtained his PhD degree in 1988. After graduation, he joined the Addis Ababa University, Ethiopia as the member of the academic staff where he served in various capacities. Currently he is a member of the research staff at the University Duisburg - Essen. His research interests are focused on power system analysis and renewable energy technologies.

Oliver Scheufeld (1976) received his Dipl.-Ing. degree in electrica engineering from the RWTH Aachen University of Aachen, Germany in 2006. He joined KEMA Consulting GmbH in Bonn, Germany in 2006 and worked in the field of Energy Markets and Regulations. In 2009, he joined the System Studies department of the "Forschungsgesellschaft für Elektrische Anlagen und Energiewirtschaft e.V. (FGH)", a research association of the German network operators and equipment manufacturers. His research interests are focused on the effects of distributed generation and the analysis of harmonics in distribution networks. He is a member of VDE and Cigré. 